\title{
Analisis Nilai-Nilai Kepemimpinan Residen Mohamad Mangoendiprojo Sebagai Pembelajaran Bagi Kaum Milenial Pada Mata Pelajaran Sejarah Di SMA Negeri 1 Terbanggi Besar T.A 2020/2021
}

\author{
Achmad Didik Khoirudin, Warto, Suryo Ediono, Muadz Assidiqi \\ Universitas Sebelas Maret \\ akhoirudin007@gmail.com
}

\section{Article History}

received $1 / 9 / 2021$

revised $1 / 10 / 2021$

accepted 1/11/2021

\begin{abstract}
Leadership is an attitude that should be owned by everyone, including students. Being a leader is certainly not an easy thing to learn. Learning must be a vehicle for the development of students' potentials not only cognitively but also effectively as well as leadership. History learning is one of the subjects that teach leadership through past figures, such as the leadership of HR Mohamad Mangoendiproejo. How to take HR Mohamad Mangoendiproejo's leadership values as lessons for millennials in history subjects at SMA Negeri 1 Terbanggi Besar for the 2021/2022 Academic Year. The paper of this study uses a descriptive qualitative research method with a case study approach. In this history subject with the Resident Leadership Values material of Mohamad Mangoendiprojo, students are expected to be able to take several things that can be used as examples of leadership traits and can be practiced in everyday life, such as courage, assertiveness, and nurturing.
\end{abstract}

Keywords: Leadership, Mohamad Mangoendiprojo, Millennials, History Education

\begin{abstract}
Abstrak
Kepemimpinan adalah sikap yang yang seyogyanya dimiliki oleh setiap orang, tak terkecuali bagi parapeserta didik. Menjadi seorang pemimpin tentu bukanlah hal yang mudah hal tersebut pelu dipelajari. Pembelajaran harus menjadi wahana untuk penumbuhkembangan potensipotensi siswa tidak hanyasecara kognitif tapi juga secara efektif seperti halnya kepemimpinan. Pembelajaran sejarah adalah salah satu mata pelajaran yang mengajarkan kepemimpinan melalui tokoh-tokoh dimasa lampau, seperti kepemimpinan HR Mohamad Mangoendiproejo. Bagaimana mengambil nilai-nilai kepemimpinan HR Mohamad Mangoendiproejo sebagai pembelajaran bagi kaum milenial pada matapelajaran sejarah di SMA Negeri 1 Terbanggi Besar Tahun Ajaran 2021/2022. Penelitian ini menggunakan metode penelitian kualitatif deskriptif dengan pendekatan studi kasus.Dalam mata pelajaran sejarah tersebut dengan materi Nilainilai Kepemimpinan Residen Mohamad Mangoendiprojodiharapkan siswa dapat mengambil beberapa hal yang dapat dijadikan contoh contohsifat pemimpin dan dapat diamalkan dalam kehidupan sehari-hari, seperti, keberanian, ketegasan, dan mengayomi.
\end{abstract}

Kata kunci: Kepemimpian, Mohamad Mangoendiprojo, Milenial, Pendidikan Sejarah

Social, Humanities, and Education Studies (SHEs): Conference Series https://jurnal.uns.ac.id/shes

p-ISSN 2620-9284

e-ISSN 2620-9292 


\section{PENDAHULUAN}

Menjadi pemimpin tidaklah mudah karena harus memiliki kemampuan mempengaruhi dan menggerakkan orang-orang agar mau dan mampu mencapai tujuan organisasi. Oleh sebab itu tidak semua orang bersedia dipilih menjadi pemimpin dan hanya sebagian orang saja yang siap menjadi pemimpin. Secara nyata pemimpin memiliki peran yang berbeda dibanding pekerjaan lainnya. Apabila seseorang yang bukan pemimpin biasanya di tuntut untuk menjadi spesialis di satu bidang namun untuk pemimpin dituntut untuk mampu memahami permasalahan -permasalahan yang ada di tiap bidang kemudian untuk diselesaikan secara bersama-sama.

kepemimpinan sebagai proses di mana satu orang memberikan pengaruh secara sengajakepada sekelompok orang dalam suatu organisasi melalui hubungan, struktur, dan panduan (Yukl,2008 dalam Basit \& Sebastian, 2017). Kepemimpinan sebagai suatu proses di mana seseorang mempengaruhi orang lain untuk mencapai tujuan dan mengarahkan dengan cara yang membuatnyalebih kohesif dan koheren (Sharma \& Jain, 3013 dalam Basit \& Sebastian, 2017). Adapun contoh pengertian kepemimpinan sebagai perilaku dikemukakan oleh Sweeney dan McFarlin (2002) yakni: "Leadership involves a set of interpersonal influence processes. The processes are aimed at motivating sub-ordinates, creating a vision for the future, and developing strategies for achieving goals", yang dapat diartikan bahwa kepemimpinan melibatkan seperangkat proses pengaruh antar orang.

Proses tersebut bertujuan memotivasi bawahan, menciptakan visi masa depan, dan mengembangkan strategi untuk mencapai tujuan.Tokoh pendidikan nasional, $\mathrm{Ki}$ Hadjar Dewantara, menurut hemat penulis, termasuk melahirkan teori kepemimpinan dalam kategori kontingensi. Dengan ajaran triloka "Ing ngarso sung tulodo, ing madyo mangun karso, tut wuri handayani", menunjukkan seorang pemimpin harus mampu bertindak sesuai dengan situasi yakni apabila di depan, ia memberikan keteladanan, apabila di tengah-tengah para bawahan, harus membangun kemauan, atau semangat pegawai; dan apabila di belakang, para pemimpin harus memberikan motivasi tiada henti kepada para anggotanya.

Generasi milenial adalah sekelompok individu yang dilahirkan dalam definisi yang samajangka waktu (Long, 2017). Milenium didefinisikan sebagai kelompok orang yang lahir antara 1981 dan 2000 (Long, 2017). Generasi milenial merupakan modal utama dalam fenomena bonus demografi. Potensi generasi milenial yang dapat dimaksimalkan akan mampu meningkatkan pertumbuhan ekonomi. Selain itu, peran generasi milenial yang merata tanpa adanya kesenjangan gender juga akan mengoptimalkan manfaat dan potensi yang ada (Kementerian Pemberdayaan Perempuan dan Perlindungan Anak \& Badan Pusat Statistik, 2018).

Ungkapan generasi Y mulai dipakai pada editorial koran besar Amerika Serikat pada Agustus1993 (Hidayatullah et al., 2018). Generasi milenial atau yang disebut juga generasi Y ini lahirsekitar tahun 1980 sampai 2000 (Hidayatullah et al., 2018). Generasi ini banyak menggunakanteknologi komunikasi instan seperti email, SMS, instant messaging dan media sosial sepertifacebook dan twitter, IG dan lain-lain, sehingga dengan kata lain generasi $Y$ adalah generasi yangtumbuh pada era internet booming (Hidayatullah et al., 2018). Jadi bisa kita katakan bahwa siswa-siswa di sekolahan hari ini adalah generasi milenial.

Sekolah adalah suatu lembaga yang mempunyai peran strategis dalam mendidik dan menyiapkan sumber daya manusia yang berkualitas dalam memegang estafet generasi sebelumnya (Johnson, 2002). Keberadaan sekolah sebagai sistem tatanan kehidupan sosial, menempatkan lembaga sekolah sebagai bagian dari sistem sosial. Sebagai bagian dari sistem dan lembaga sosial, sekolah harus peka dan tanggap dengan harapan dan tuntutan masyarakat sekitarnya. Sekolah diharapkan menjalankan fungsinya dengan mencerdaskan kehidupan bangsa dengan optimal dan mengamankan diri dari pengaruh negatif lingkungan sekitar (Benninga, 2003: 19; 
Damon, 2002: 9). Maka dari itu, penelitian ini berusaha untuk menyajikan peran sekolah dalam menciptakan iklim pembelajaran pendidikan karakter kepada siswa.

Salah satu mata pelajaran yang memiliki muatan pendidikan karakter adalah pendidikan Sejarah (Althof, 2006; Aman, 2011; Wineburg, 2001). Mata pelakaran sejarah merupakan pelajaran yang menanamkan pengetahuan, sikap dan nilai-nilai proses mengenai perubahan dan perkembangan masyarakat Indonesia dari dulu hingga sekarang. Nilai-nilai yang terkandung dalam pembelajaran sejarah Indonesia yaitu nilai keilmuan, nilai informatif, nilai etika dan nilai nasioanlisme (Kochar, 2008).

Maka jelas bahwa pelajaran sejarah Indonesia tidak hanya menunjang pengetahuan siswa melainkan memuat aspek lainnya yang dibutuhkan siswa dalam kehidupan. Mata pelajaran sejarah memberikan pembelajaran yang harus dimaknai. Belajar sejarah merupakan pintu untuk mempelajari dan menemukan hikmah terhadap peristiwa yang terjadi (Kartodirdjo, 1992; Kuntowijoyo, 1995). Pembelajaran sejarah memberikan ruang bagi peserta didik untuk memahami kemanusiaan dari berbagai aspek. Belajar sejarah diyakini melahirkan kesadaran tentang hakikat perkembangan budaya dan peradaban manusia, hasil belajar inilah yang kemudian dikenal sebagai kesadaran sejarah (historical consciousness).

Seperti kita ketahui bersama peserta didik sekarang yang notabene adalah kaum milenial banyak yang kehilangan nilai-nilai sosial, nilai-nilai kemanusiaan dll. Hal ini bukanlah tanpa sebab, ini dikarenakan peserta didik cenderung menghabiskan wktunya dengan menggunakan tekhnologi. Sehingga inimenyebabkan nilainilaikepemipinan dalam diri siswa belum sepenuhnya terlihat. Oleh karena itu peserta didik perlu mendapatkan contoh nilai-nilai kepemimpinan, terutama dari tokoh sejarah yang ada di daerah tersebut, seperti yang dilakukan oleh tokoh Mohamad Mangundiprojo, yakni salah satu tokoh Lampung yang menjabat sebagai Residen.

Haji $(H)$ Raden $(\mathrm{R})$ Muhamad Mangoendiprojo dilahirkan pada tanggal 5 Januari 1905 di Sragen, sebagai putera ketiga Raden Ngabehi (R. Ng.) Mardjan Sastromardjono dengan R. Siti Wahjoenah. Dua kakak Mohamad, R. Siti Aminah dan R. Siti Djenah, masing-masing menikah dengan seorang Komisaris Pos dan Klerek Pos. Adik mohamad, R. Soewarno meninggal dalam usia muda, sedang yang bungsu R. Siti Ismirah Supadi menikah dengan seorang guru. Ibu mohamad yang biasa dipanggil Ibu Ayu, meninggal tidak lama setelah melahirkan Siti Ismirah. Si Bungsu kemudian dibesarkan oleh ibu sambungan, Raden Ajeng (R.A) Tasri, putera Bupati Bayolali. Mardjan Sastromardjono terakhir bekerja sebagai Asisten Kolektur Opium Regie di Solo adalah putera keenam H.R. Hasan Zainal Mustofa, Penghulu Landraad (Penghulu Pengadilan Agama) Sragen, sedang Ibu Ayu adalah putera R. Mangoen Admodjo, Patih Madiun (Moehkardi, 1993).

\section{METODE}

Metode penelitian yang digunakan oleh peneliti dalam penelitian ini adalah metode kualitatif. Menurut Creswell (2016) penelitian kualitatif adalah jenis penelitian yang mengeksplorasi dan memahami makna di sejumlah individu atau sekelompok orang yang berasal dari masalah sosial. Penelitian kualitatif secara umum dapat digunakan untuk penelitian tentang kehidupan masyarakat, sejarah, tingkah laku, konsep atau fenomena, masalah sosial, dan lain-lain. Salah satu alasan mengapa menggunakan pendekatan kualitatif adalah pengalaman peneliti dimana metode ini dapat menemukan dan memahami apa yang tersembunyi dibalik fenomena yang kadangkala merupakan suatu yang sulit untuk dipahami. Penelitian ini menggunakan metode penelitian kualitatif deskriptif dengan pendekatan studi kasus. Studi kasus meliputi studi tentang suatu kasus dalam kehidupan nyata, dalam konteks saat ini (Creswell, 2018). 


\section{HASIL DAN PEMBAHASAN}

Memuat hasil dan pembahasan tentang penelitian yang dilakukan, termasuk tabel, dan gambar yang disajikan. Penomoran harus diberikan pada tabel dan gambar berdasarkan urutannya.

Pasca lengsernya Mr. Gele Harun pada tahun 1955 kemudian beliau digantikan oleh HR. Mohamad Mangoendiprojo yang dilakukan oleh pemerintahan pusat berdasarkan pada kemampuan dan pengalaman kepemimpinan beliau selama menjadi tentara dan bupati Ponorogo yang sukses dan disegani.Setelah lima tahun bertugas di Ponorogo, pada tanggal 1 November 1955, Mohamad memperoleh promosi dan diangkat menjadi Residen Lampung oleh menteri dalam negeri Mr. A. Soenarjo yang menilai HR. Mohamad Mangoendiprojo sebagai orang jawa yang santri dan dinilai akan mampu meredam pertentangan antara penduduk asli Lampung yang santri dengan penduduk transmigran Jawa yang Islam Abangan.

1. Peranan Mohamad Mangoendiprojo Sebagai Residen Lampung

a. Menyelesaikan Perseteruan CTN di Lampung

Mohamad Mangoendiproojo menjadi Residen Lampung dimulai 1 November 1955, pada masa awal menjadi residen, Mohamad langsung dihadapkan pada permasalahan yang cukup kritis yaitu mengurus transmigran eks Corps Tjadangan Nasional (CTN). Sebagai bagian dari konsep pertahanan Negara kala itu, istilah "cadangan" sendiri mulai dikenal pada masa demokrasi liberal (1950-1959) dengan nama Corps Tjadangan Nasional (CTN) hingga Pemberlakuan Wajib Militer. Anggota CTN yang bertransmigrasi ke Lampung ini kemudian bersiterus dengan Mohamad Mangoendiprojo karena tidak senang dengan kebijakan-kebijakan yang dibuat oleh Mohamad Mangoendiprojo.

Adapun itu Mohamad Mangoendiprojo dinalai tidak cocok karena bukan putra asli lampung yang menjadi Residen Lampung melainkan adalah orang Jawa yang baru saja menginjakkan kakinya ditanah Lampung karena diangkat menjadi Residen Lampung, selain itu Mohamad Mangoendiprojo adalah orang yang tegas dalam mengambil keputusan dan orang taat peraturan juga tegas yang membuat CTN dan Mohamad Mangoendiprojo sama-sama tak ingin untuk mengalah. Namun, akhirnya kedua belah pihak menyadari bahwa mereka sama-sama pernah berjuan dibidang bersenjata, untuk meredakan persiteruan tersebut dilakukanlah pendekata musyawarah. Melalui kerjasama antara Kementerian Dalam Ngeri dan Kementerian Pertahanan, masalah CTN di Lampung akhirnya dapat diselesaikan dengan baik dan tanpa kendala apapun.

b. Menangani Kasus Beras di Lampung

Awalnya Sumatera Selatan tidak kesulitan beras karena di Palembang sudah cukup banyak menghasilkan beras, karena Sumatera selatan tidak kesulitan beras awalnya, Sumatera Selatan mengekspor beras keluar negeri, namun di Sumatera Selatan mulai terserang hama pada tahun 1933, baru tersebar ke desa-desa di sumatera selatan pada tahun 1954, hingga membuat Sumatera Selatan mau tidak mau harus menyedot beras dari Lampung untuk bisnis ekspor beras dengan negara lain yang telah berjalan agar tidak terputus.

Daerah Lampung yang dikenal sebagai gudang beras Provinsi Sumatera Selatan, karena saat itu terjadi kesulitan beras maka akibatnya beras Lampung tersedot tanpa batas ke Daerah Sumatera Selatan seperti Palembang, hal ini yang membuat Mohamad Mangoendiprojo melakukan tindakan sesegera mungkin demi rakyat Lampung. Beliau melakukan tindakan dengan cara mengirimi surat kepada Gubernur Sumatera Selatan mengusulkan agar masalah perdagangan beras dari Lampung ke daerah lain ditertibkan.

Namun Usul Mohamad Mangoendiprojo tersebut rupanya tidak diperhatikan oleh atasannya. Demi melindungi rakyat di daerahnya, Mohamad Mangoendiprojo kemudian membuat keputusan drastis, melarang perdagangan 
beras ke luar daerah Lampung. Tindakan yang dilakukan Mohamad Mangoendiprojo secara tegas memang sangat mengejutkan namun inilah tindakan yang perlu dilakukan agar Lampung tidak mengalami kekurangan beras, akan tetapi tindakan Mohamad Mangoendiprojo mendapatkan teguran dari Menteri Dalam Negeri yang secara langsung turun menangani kasus beras di Lampung.

Kasus beras tersebut kemudian memberikan Mohamad Mangoendiprojo inspirasi untuk membuat gerakan di Lampung, menuntut status propinsi bagi daerah Lampung, terpisah dari propinsi Sumatera Selatan dan disinilah inspirasi pergerakan Mohamad Mangoendiprojo dimulai demi menjadikan Keresidenan Lampung sebagai Provinsi Lampung.

c. Memprakarsai seluruh elemen Masyarakat Lampung untuk Menjadikan Lampung Sebagai Daerah Tingkat I (Provinsi)

Bersama 3 orang bupati di daerah Lampung yang semuanya berasal dari putera daerah tersebut, Mohamad Mangoendiprojo selaku Residen Lampung turut menanda tangani petisi mendukung tuntutan tersebut. Gerakan tersebut akhirnya berhasil, pada tahun 1964, secara resmi daerah Lampung dinyatakan sebagai propinsi. (Moehkardi, 1993:189)

Mohamad Mangoendiprojo bersama 3 oang bupati di daerah Lampung yaitu Zaenal Abidin Pagar Alam, A Somad dan Hasan Basri mengeluarkan manifesto politi berupa "petisi" yang isinya meminta kepada pemerintah pusat untuk menjadikan daerah Lampung sebagai Daerah Otonomi Tingkat I (Provinsi). Mohamad Mangoendiprojo selaku Residen Lampung turut menandatangani petisi mendukung tuntutan tersebut.

Kebijakan politik ini kemudian menjadi pemicu masyarakat Lampung untuk semakin semangat memperjuangkan keinginan memiliki daerah sebagai daerah Provinsi. Gerakan tersebut akhirnya pada tahun 1964, secara resmi daerah Lampung dinyatakan sebagai propinsi. Ketika status provinsi itu diresmikan, Mohamad Mangoendiprojo telah pensiun sebagai Residen Lampung, terhitung sejak 1 Juli 1962 dengan pangkat terakhir Golongan F VI. Pra karsa Residen Mohamad Mangoendiprojo kemudian dilanjutkan oleh Residen penggantinya Zaenal Abidin Pagar Alam.

2. Pelaksanaan dalam pembelajaran Sejarah

Menurut Malik dalam buku Dirman dan Cicih Juarsih menjelaskan bahwa pembelajaran adalah suatu kombinasi yang tersusun meliputi unsur-unsur manusiawi, material, fasilitas, perlengkapan, dan prosedur yang saling mempengaruhi untuk mencapai tujuan pembelajaran. Manusia yang terlibat dalam sistem pembelajaran terdiri dari peserta didik, guru, dan tenaga lainnya, misalnya tenaga laboratorium. Material, meliputi buku-buku, papan tulis dan kapur, fotografi, slide dan film, audio dan video tape. Fasilitas dan perlengkapan, terdiri dari ruangan kelas, perlengkapan audio visual, juga komputer. Prosedur, meliputi jadwal dan penyampaian informasi, praktik, belajar, ujian, dan sebagainya.

Berdasarkan batasan di atas dapat dikatakan bahwa pembelajaran adalah suatu proses kombinatif yang interaktif dari berbagai komponen yang terlibat dalam pembelajaran untuk mencapai tujuan pembelajaran yang telah ditetapkan. Komponen peserta didik dalam proses pembelajaran tersebut adalah subjek belajar yang mempelajari materi atau bahan ajar dengan prosedur, bimbingan dan arahan dari guru yang didukung oleh fasilitas memadai untuk mencapai tujuan pembelajaran yang telah ditetapkan. (Dirman dan Cicih Juarsih, 2014 : 40).

Nilai-nilai kepemimpinan Mohamad Mangoendiprojo disini bukan sebagai mata pelajaran yang berdiri sendiri, tapi disini sebagai konseptual yang diintegrasikan dalam perangkat pembelajaran seperti RPP, silabus, modul pembelajaran dan evaluasi pembelajaran yang akan dilaksanakan pada proses pembelajaran sejarah yang 
sedang berlangsung. Di dalam kegiatan belajar mengajar tersebut terjadi interaksi diantara peserta didik menyangkut materi pelajaran. Setelah pelajaran selesai maka akan dicapai tujuandari analisis nilai-nilai kepemimpinan Mohamad Mangoendiprojo sebagai pembelajaran bagi para pelajar yang hari ini masuk dalam kategori kaum milenial

\section{SIMPULAN}

Dari kepemipinan Mohamad Mangoendiprojo kita bisa mengambil beberapa hal yang bisa kita ajarkan kepada para peserta didik, dianntaranya adalah:

1. Ketegasan

Kita dapat melihat bagaimana ketegasan beliau dalam menjalankan peraturan yang sudah ada, bahkan beliau harus siap berkonflik dengan kawan-kawannya dahulu di CTN.memang sebagai pemimpin kerap kali kita dihadapkan dengan hal-hal yang berat dalam pengambilan keputusan karena menjaga agar keputusan kita dapat diterima oleh semua kalangan akhirnya kita melenturkan peratran, tetapi hal ini tidak berlaku pada Mohamad Mangoendiprojo beliau tetap kekeh menjalankan peraturan yang ada dan siap menaggung risiko yang akan datang.

2. Keberanian

Ketika terjadi gagal panen di daerah Sumatera Selatan daerah Lampung diminta untuk mengirimkan berasnya ke daerah Sumatera Selatan, tentu hal ini akan berakibat sangat buruk bagi masyarakat Lapung sendiri, karena berasnya tersedot, tetapi karena keberanian Mohamad Mangoendiprojo mengirim surat surat kepada Gubernur Sumatera Selatan mengusulkan agar masalah perdagangan beras dari Lampung ke daerah lain ditertibkan.hal ini tentu membutuhkan keberanian yang luar biasa dari seorang pemipin karena disatu sisi beliau harus melawan terhadapatasanya dan beliau paham akan risikonya,tetapi demi melindungi rakyatnya beliau siap dengan risiko yang dihadapi.

3. Menjadi pengayom untuk rakyat

Buntut panjang dari kekurangan beras di Sumatera Selatan akhirnya membuat Mohamad Mangoendiprojo bersama 3 orang bupati di daerah Lampung yang semuanya berasal dari putera daerah Lampug membuat petisi yang isinya meminta kepada pemerintah pusat untuk menjadikan daerah Lampung sebagai Daerah Otonomi Tingkat I (Provinsi). Hal ini beliau lakukan adalah demi mengayomi masyarakat, sehingga masyarakat menyambut dengan penuh suka cita.

Hal-hal diatas adalah merupakan contoh kepemimpinan yang nyata dari seorang Residen yakni Haji $(H)$ Raden (R) Mohamad Mangoendiprojo atau HR Mohamad Mangoendiprojo yang dapat dijadikan contoh oleh peserta didik SMA Negeri 1 Terbanggi Besar, karena peserta didik hari ini adalah calon pemimpin dimasa mendatang, tentu kepemimpinan tidak sertamerta lahir begitu saja, halitu perlu digodk dan dipelajari. Penulis berharap pelajaran sejarah Di SMA Negeri 1 Terbanggi Besar tidak hanya menjadi pembelajaran yang menekankan pada aspek kognitif saja tetapi juga aspek afektif seperti kepemimpinan, karena pada mata pelajaran sejarah terdapat banyak tokoh yang mempu dijadikan contoh dan tauladan dalam hal kepemimpinan, seperti Haji (H) Raden (R) Mohamad Mangoendiprojo

\section{DAFTAR PUSTAKA}

Basit, A., \& Sebastian, V. (2017). Impact of Leadership Style on Employee Performance (a Case Study on a Private Organization in Malaysia), 5(2), 112130.

Benninga dkk. 2003. "The Relationship of Character Education Implementatio and Academic Achievement in Elementary Schools". Journal of Research in Character Education, Vol.1 No.1, pp. 19-32 
Creswell, J. (2016). Riset Pendidikan: Perencanaan, Pelaksanaan, dan Evaluasi Riset Kualitatif dan Kuantitatif Edisi Kelima, terjemahan Helly Prajitno Soetjipto dan Sri Mulyantini Soetjipto, Yogyakarta: Pustaka Pelajar

Dirman dan Cicih Juarsih. (2014). Teori Belajar dan Prinsip-prinsp Pembelajaran yang mendidik. Jakarta: PT. Rineka Cipta.

Hidayatullah, S., Waris, A., \& Devianti, R. C. (2018). Perilaku Generasi Milenial dalam Menggunakan Aplikasi Go-Food. Jurnal Manajemen Dan Kewirausahaan, 6(2), 240-249.

Johnson, Elaine B. 2002. Contextual Teaching and Learning. California: Corwin Press

Kartodirjo sartono. 1992. Pendekatan ilmu sosial dalam sejarah: Jakarta. Gramedia PustakaUtama.

Kochar, S.K. (2008). Pembelajaran Sejarah. Jakarta: PT Grasindo.

Kuntowijoyo. (2003). Metodologi sejarah. Yogyakarta: Tiara Wacana yogya.

Long, S. (2017). Exploring Which Leadership Styles are Effective with Millennial Employees. ProQuest Dissertations and Theses, 171. Retrieved from https://search.proquest.com/docview/1978512367?accountid=26642\%0 http://link.periodicos.capes.gov.br/sfxlcl41?url_ver=Z39.882004\&rft_val_ $\mathrm{mt}=$ info:ofi/fmt:kev:mtx:dissertation\&genre=dissertations+\%26+theses\&s d=ProQ:ProQuest+Dissertations+\%26+Theses+Globa 01 Oktober 2021

Moehkardi. (1993). R. Mohamad Dalam Revolusi 1945 Surabaya, Sebuah Biografi. Jakarta: Lima Sekawan.

Sweeney, P.D., dan McFarlin, D.B. (2002). Organizational Behaviour: Solution for Management. New York: McGraw Hill.

Wineburg, S. (2001). Historical Thinking and Other Unnatural Acts: Charting the Future of Teaching the Past. Philadelphia: Temple University Press. 